\title{
Safeguard Provisions
}

BILLY MELO ARAUJO AND STEPHEN BRITTAIN

\subsection{Introduction}

Safeguard provisions are a common feature of international trade agreements. They provide signatories with the means of expeditiously suspending the operation of the provisions of the agreement where their operation is causing, or threatens to cause, economic disruption. The Protocol has its very own safeguard provision in the form of Protocol Article 16 and the same provision is replicated, more or less verbatim, in the Trade and Cooperation Agreement (TCA) Article 773. In the context of the Protocol, safeguard provisions seem particularly problematic as they provide a legal mechanism through which the EU and the UK could impose trade barriers within the island of Ireland, thus defeating what is arguably the primary objective of the Protocol.

The aim of this chapter is to discuss the main features of Protocol Article 16 and Article 773 TCA. In particular, the chapter outlines the main differences between these safeguards and those safeguards inspired by the law of the World Trade Organization (WTO) that are typically included in standard trade agreements. It also explores how the distinctive features of Article 16 of the Protocol may impact the judicial review of safeguard measures. The chapter is structured as follows. First, we consider safeguards as regulated under the law of the WTO; second, we consider the safeguard provisions contained in the Protocol and the TCA; and, finally, we briefly consider the extent to which the invocation of the safeguard provisions contained in the WA and the TCA might be capable of being judicially reviewed both under the arbitration provisions of the TCA and as a matter of EU and UK law. 


\subsection{WTO Safeguards}

The WTO safeguards regime allows WTO members temporarily to reimpose trade barriers in situations where sudden increases in imports resulting from unforeseen events cause or threaten to create injury to domestic industries. They differ from other so-called trade remedies permitted under WTO law whereby WTO members may apply trade barriers to protect domestic industries from unfair trade practices - namely dumping ${ }^{1}$ and illegal subsidization ${ }^{2}-$ adopted or originating from other parties. Safeguards differ in that they constitute responses to difficult circumstances that result from trade liberalization.

WTO safeguards are governed by Article XIX of the General Agreement on Tariffs and Trade (GATT) ${ }^{3}$ and the WTO Agreement on Safeguards (AoS). ${ }^{4}$ In essence, three requirements must be satisfied before this provision may be invoked to suspend the obligations of a state: (i) there must be sudden increase in imports; (ii) this increase must be due to an unforeseen development; and (iii) the increase must cause, or threaten to cause, serious injury to domestic producers.

WTO safeguards typically take the form of increased tariffs, tariff-rate quotas or quantitative restrictions. Such measures may be applied only following an investigation carried out by competent national authorities. ${ }^{5}$ In the context of such investigations, reasonable public notice must be given to all interested parties and appropriate means must be given to such parties to present evidence and give their views. In many jurisdictions, private applicants have the right to request authorities to initiate a safeguards investigation. ${ }^{6}$

${ }^{1}$ Agreement on the Implementation of Article VI of GATT, Antidumping Agreement, 15 April 1994, 1868 UNTS 201.

2 Agreement on Subsidies and Countervailing Measures, 15 April 1994, Marrakesh Agreement Establishing the World Trade Organization, Annex 1A, 1869 UNTS 14.

3 GATT 1947: General Agreement on Tariffs and Trade, 30 October 1947, 61 Stat. pt. 5, 55 UNTS 194.

4 Agreement on Safeguards, Annex 1A to the Marrakesh Agreement 15 April 1994, 1869 UNTS 154 .

5 Art 3 of the WTO Agreement on Safeguards, Annex 1A to the Marrakesh Agreement 15 April 1994, 1869 UNTS 154.

${ }^{6}$ See, in the case of the UK, s 31 of the Trade Remedies (Increase in Imports Causing Serious Injury to UK Producers) (EU Exit) Regulations 2019. 


\subsection{Safeguards in the Context of the EU-UK Trade Relationship}

The Protocol and the TCA include safeguard clauses which may usefully be subdivided into two categories. First, the TCA includes WTO-type safeguards, allowing parties to re-erect trade barriers where increased imports cause or threaten serious injury to the importing country's domestic industry. ${ }^{7}$ Second, and the main focus of this chapter, sui generis safeguard clauses are available that allow the parties to suspend their obligations where certain exceptional circumstances are present.

The first of such safeguards is found in Protocol Article 16 which allows the parties unilaterally to take appropriate safeguard measures where the application of the Protocol leads to serious economic, societal or environmental difficulties that are liable to persist; or a diversion of trade. No guidance is provided as to the form that safeguard measures should take, except that measures adopted in response to such difficulties must be restricted with regard to their scope and duration to what is 'strictly necessary' to remedy the situation. ${ }^{8}$ The second relevant safeguard provision, Article 773 TCA, uses fairly similar language. It allow parties to apply safeguard measures '[i]f serious economic, societal or environmental difficulties of a sectorial or regional nature, including in relation to fishing activities and their dependent communities, that are liable to persist arise'.

In addition to the substantive standards set out under Protocol Article 16 and Article 773 TCA, there are procedural requirements that must be fulfilled prior to adoption of a safeguard measure. Any party wishing to adopt a safeguard must notify its intention to do so to the other party and enter into consultations with a view to finding an agreed acceptable solution. This confers a significant amount of discretion on the parties when choosing whether to adopt safeguards. The relevant party must also refrain from adopting safeguards until one month after the date of the notification mentioned above, unless there are exceptional circumstances that justify immediate action.

Both safeguard provisions outlined here differ significantly from WTO safeguards. In terms of substantive requirements, Protocol Article 16 and

7 Art 32 TCA.

${ }^{8}$ In July 2021, the UK government announced that it had considered invoking Article 16, setting out why it had thought such a move would be justified, but stated that it had decided not to do so at that time; see HM Government, Northern Ireland Protocol: The Way Forward (CP 502, July 2021), paras 28-34. This is considered further in 'Update: Developments from July 2021 to September 2021' at the front of this book. 
Article 773 TCA may be applied in multiple broad factual scenarios and, seemingly, even in instances where adverse consequences of the Protocol were foreseeable. The differences in procedural requirements are also potentially significant. Whereas WTO safeguards must be adopted following an investigation carried out by relevant national authorities, there is no such obligation under Protocol Article 16 and Article 773 TCA. In short, compared to WTO safeguards, these provisions seem to confer a considerable margin of discretion on the parties.

\subsection{Dispute Settlement}

\subsubsection{Judicial Review under EU Law}

In the context of the EU, WTO safeguards are subject to the judicial review mechanisms established under the EU Treaties. ${ }^{9}$ In the absence of a special judicial procedure, the same applies to safeguard measures under Article 16 of the Protocol, with the two most probable avenues being either annulment ${ }^{10}$ or preliminary reference proceedings. ${ }^{11}$ However, in both instances, private applicants will face significant obstacles in challenging safeguard measures.

An action for annulment is a judicial mechanism that allows interested parties to bring a direct action against and challenge the legality of EU acts. Under this procedure, EU safeguard measures could be reviewed on the grounds of lack of competence (eg, an EU institution uses the incorrect legal basis for an act), infringement of procedural requirements (eg, failure to explain the rationale of the action taken) or infringement of the EU Treaties or any rule relating to their application. ${ }^{12}$ The last ground for review includes breach of binding international agreements entered into by the $\mathrm{EU}^{13}$ and would encompass challenges against EU safeguards for alleged breaches of substantive and procedural requirements set out under the Protocol.

However, there are several conditions that must be met by interested parties wishing to bring an action for annulment before the Court of Justice of the European Union (CJEU). First, any claim must be made within two months from the date of the publication of the measure being

9 E Vermulst and J Sud, 'European Union: An Imperfect and Time-Consuming System' in M Yilmaz (ed), Domestic Judicial Review of Trade Remedies (Cambridge University Press 2013)190.

${ }^{10}$ Art 256(1) TFEU.

11 Art 267 TFEU.

12 Art 263(2) TFEU.

13 AH Türk, Judicial Review in EU Law (Edward Elgar 2009) 127. 
challenged, its notification to the plaintiff, or its coming to the knowledge of the latter. ${ }^{14}$

Second, only EU acts that produce binding legal effects can be subject to review. ${ }^{15} \mathrm{CJEU}$ case law has long recognized not only that WTO safeguard measures are acts that may be the subject of an action of annulment ${ }^{16}$ but also that the refusal by the European Commission to open a trade remedies investigation can be challenged by persons who filed a complaint requesting such investigation. ${ }^{17}$ Whether the refusal to apply safeguard measures under Article 16 of the Protocol would be reviewable is less clear. While CJEU case law permits the review of a decision not to open an investigation where individuals have specific procedural rights in the decision-making process, ${ }^{18}$ the same does not apply to instances where such rights do not exist. ${ }^{19}$ Given that there is no procedure available for private applicants to request the $\mathrm{EU}$ to open safeguard investigations or adopt a safeguard under Article 16 of the Protocol, it seems unlikely that a decision by the EU not to apply safeguards would be deemed a reviewable act.

Annulment actions may be lodged by EU institutions, EU member states, some EU bodies and natural or legal persons. The European Parliament, the Council, the Commission and EU member states ${ }^{20}$ (socalled privileged applicants) may bring an action for annulment directly before the CJEU without establishing that they have an interest, since they are assumed to have an interest in ensuring compliance with EU law. ${ }^{21}$ For example, Ireland could file an action for annulment against an EU act applying a safeguard measure which it considers disproportionate because either its duration or its scope goes beyond what is strictly necessary to achieve its stated objective.

Annulment actions filed by natural or legal persons ${ }^{22}$ (so-called nonprivileged applicants) are more problematic because of restrictive standing requirements. ${ }^{23}$ Indeed, for such applicants, the most significant

14 Art 263(6) TFEU.

15 Art 263(1) TFEU.

16 Case C-7601 P, Eurocoton and Others v Council [2003] ECR I-1091.

17 Vermuslt and Sud (n 9) 184.

18 Ibid.

19 I Willems, B Natens and A Moroni, 'Hurdles to Litigating Trade Defence Measures before EU Courts' (2020) 54(6) Journal of World Trade 922.

20 Art 263(2) TFEU.

21 Art 268 TFEU.

22 Art 263(4) TFEU.

23 M Rhimes, 'The EU Courts Stand Their Ground: Why Are Standing Rules for Direct Actions so Restrictive?' (2016) 9(1) European Journal of Legal Studies 103. 
barrier to review is the standing requirement. Unless applicants are addressed in the safeguard measure, they would have to show either that (i) they are directly concerned by a regulatory act not entailing implementing measures or that (ii) they are both directly and individually concerned by the safeguard measure. ${ }^{24}$

The test of direct concern is relatively easy to satisfy since it entails demonstrating that the action taken affects the legal situation of the applicant directly and that no further implementing measures are required. ${ }^{25}$ Irish firms adversely affected by the increase in barriers to trade between the EU and Northern Ireland, as a result of the EU's decision to trigger Protocol Article 16, should be able to make the case that their legal position had been affected. However, the measure being challenged would also have to be considered to be a regulatory act - that is, 'an act of general application, apart from legislative acts'. ${ }^{26}$

The term regulatory act is understood to include actions adopted via a procedure other than ordinary legislative procedures set out under EU law. ${ }^{27}$ This excludes acts such as EU regulations and directives but includes implementing regulations which are typically used by the EU to impose trade restrictive measures. ${ }^{28}$ As an example, the European Commission's botched attempt to use Article 16 of the Protocol as a legal basis for the imposition of export restrictions on the movement of Covid-19 vaccines between the EU and Northern Ireland ${ }^{29}$ would have taken the form of a Commission implementing regulation which would qualify as a regulatory act. However, in addition, a regulatory act must not entail implementing measures. If implementation is carried out by EU member states, applicants may struggle to challenge the underlying EU act. In the area of trade remedies, such as WTO safeguards, applicants have had difficulties in justifying standing because such remedies are, in practice, applied by national customs authorities. ${ }^{30}$ Similar standing barriers are likely to be faced by non-privileged applicants challenging EU safeguard measures under Article 16 of the Protocol.

24 Art 264(4) TFEU.

25 Ibid.

26 Case C-583/11 P Inuit Tapirit Kanatami and others $v$ European Parliament and Council EU:C:2013:625.

27 Inuit Tapiriit Kanatami, at para 58.

28 Willems, Natens and Moroni (n 19) 922.

29 J Curtis, Northern Ireland Protocol: Article 16 and EU Vaccine Export Control, 3 February 2021, House of Commons Library, https://commonslibrary.parliament.uk /northern-ireland-protocol-article-16-and-eu-vaccine-export-controls/.

30 Willems, Natens and Moroni (n 19) 923. 
The condition of 'individual concern' requires a demonstration that the act affects the applicants by reason of certain attributes that are peculiar to them or by reason of circumstances in which they are differentiated from all other persons. The individual concern requirement has been interpreted and applied so restrictively under EU case law that it is nigh on impossible for non-privileged applicants to satisfy the standing requirements. This would certainly be the case as regards challenging safeguard measures which are by their very nature measures of general application which do not target specific individuals.

There are circumstances where the 'individual concern' test has been relaxed. The CJEU has found that a person may be individually concerned by an EU act where they experience economic difficulties of a serious nature as a consequence of such act. In Extramet, ${ }^{31}$ the CJEU found that an applicant was individually concerned by a regulation imposing anti-dumping duties because they were both the largest importer and the end user of the product targeted by the duties. This ruling has proved to be the exception rather than the rule in CJEU case law, however, with courts generally denying individual concern in cases where applicants have shown that they are more severely affected by an $\mathrm{EU}$ act than other addressees. ${ }^{32} \mathrm{CJEU}$ case law on trade remedies has also recognized that importers and exporters may be individually concerned where they were part of the original investigation which led to the adoption of remedies (eg, producers who filed or supported the complaint) or were somehow involved in that investigation (importers or exporters whose data were used in the context of the investigation). ${ }^{33}$ However, in the absence of any procedural rights granted to individuals in the decision-making process underpinning safeguards under Protocol Article 16, it seems unlikely that private applicants would be able to argue successfully the existence of an individual concern.

Another potential avenue for judicial review under EU law is the preliminary reference procedure. ${ }^{34}$ Under this procedure, if a question concerning the validity of an EU act arises in the context of a domestic judicial dispute, the relevant domestic tribunal or court may - if a final court, must - refer the question to the CJEU. Should litigation arise at a domestic level as a consequence of the application of a safeguard measure, a preliminary reference request may be made to the CJEU.

31 Case C-358/89 Extramet v Council [1991] ECR 2501.

32 Türk (n 13) 91-93.

33 Willems, Natens and Moroni (n 19) 924.

34 Art 267 TFEU. 
For example, if the EU were to decide to impose tariffs or regulatory compliance checks on goods traded between Northern Ireland and Ireland, those checks would have to be carried out by Irish customs authorities. The legality of such checks by Irish authorities could then be challenged before the competent Irish courts who could decide to refer a question concerning the validity of the safeguards to the CJEU.

One important limitation associated with the preliminary reference procedure, however, is that domestic courts have some leeway in deciding whether or not to refer a question to the CJEU. ${ }^{35}$ Judicial bodies are not required to refer questions to the CJEU unless it is considered that a ruling is needed in order to resolve the domestic judicial dispute. The only judicial bodies that are required to refer questions of EU law to the CJEU are those against whose decisions there is no judicial remedy ${ }^{36}$ - that is, those courts or tribunals whose rulings cannot be appealed. However, even such courts may decide against referring a preliminary question where the answer to the question will not affect the outcome of the case, where the question has previously been answered, or where the answer to the question is so obvious that no further clarification is required. ${ }^{37}$

Compared to annulment proceedings, preliminary references offer a realistic path for judicial review of Protocol Article 16 safeguards for private applicants. It remains, however, fraught with difficulties. The procedure is time-consuming and applicants have little control over the procedure since the decision whether to refer or not is ultimately made by the national courts.

\subsubsection{Judicial Review under UK Law}

In addition to decisions relating to safeguards being capable of being challenged by way of proceedings before the EU courts, it is also possible that a decision by the UK government whether or not to invoke a safeguard provision in either the WA or the TCA may be capable of being challenged by way of judicial review proceedings before the UK courts. Applicants for judicial review in the UK would be required to meet the requirements as to time limits laid down in the relevant procedural rules of the jurisdiction concerned. ${ }^{38}$

35 A Cuyvers, 'Preliminary References under EU Law' in E Ugirashebuja, J Ruhangisa, T Ottervanger and A Cuyvers (eds), East African Community Law (Brill 2017) 279.

${ }^{36}$ Art 267(3) TFEU.

37 Case 283/81 CILFIT ECLI:EU:C:1982:335, paras 10-16.

${ }^{38} \mathrm{Eg}$, in England and Wales, Rule 54.5. of Part 54 of the Civil Procedure Rules, in the absence of an enactment providing for a shorter time period, requires that a claim be filed 
Applicants for judicial review in the UK must likewise satisfy a standing requirement. However, under UK law an applicant need only show that they have a 'sufficient interest' in order to challenge a decision. The issue of whether a particular applicant has standing is assessed 'against all the factual and legal circumstances of the case'. ${ }^{39}$ While the issue of whether an applicant has standing is a jurisdictional one, which the parties are not free to dispense with by agreement, ${ }^{40}$ the rules on standing are liberally applied by the courts. In determining whether an applicant has a sufficient interest to challenge a particular decision, consideration is given to, inter alia, the strength and importance of the grounds of challenge, ${ }^{41}$ the extent to which the personal interests of the applicant are impacted by the decision under review, ${ }^{42}$ and, importantly, the question of whether the proceedings raise an issue relating to the public interest in which the applicant has an interest but one which is shared by the generality of the public. ${ }^{43}$ The rules of standing in UK judicial review proceedings also protect the role of campaign and interest groups in the context of public interest litigation. ${ }^{44}$ It is therefore clear that the standing requirements for bringing judicial review proceedings under UK law are considerably more liberal than those arising under Article 264(4) TFEU.

However, even though an individual is likely to be able to satisfy the standing requirements to bring judicial review proceedings, it is somewhat unlikely that the UK courts would be willing to review the substance of a decision by the UK government as to whether or not to invoke the safeguard provisions under the WA and the TCA, for three reasons. First, the decision as to whether to invoke the safeguard provisions under the WA and the TCA involves the assessment of complex factual and technical issues, including whether the aspect of the Agreement which is being suspended has caused serious economic, social or environmental disruption or a diversion of trade, and the courts will review such matters only on limited grounds. ${ }^{45}$ Second, the courts tend to be reluctant to

'(a) promptly; and (b) in any event not later than 3 months after the grounds to make the claim first arose'.

39 H Woolf, J Jowell, C Donnelly and I Hare, De Smith's Judicial Review (8th edn, Thomson Reuters 2018) ('De Smith'), § 2-027.

40 Ibid, $\$ 2-10$.

41 Ibid, $\$ 2-31$.

42 Ibid, $\$ \$ 2-032-2-034$.

43 Ibid, $\$ \$ 2-035-2-036$.

44 Ibid, $\$ \$ 2-039-2-045$.

45 Ibid, \$\$ 11-043-11-051. 
review decisions involving the exercise of the kind of essentially political judgements ${ }^{46}$ which would undoubtedly be involved in deciding whether to invoke a safeguard provision under the WA or the TCA. Third, and more specifically, the courts are often reluctant to interfere with decisions in the realm of international relations ${ }^{47}$ For all of these reasons, it seems unlikely that judicial review proceedings initiated in the UK courts challenging the substantive decision by the UK government to invoke a safeguard provision would be successful.

However, a procedural challenge to the exercise or non-exercise of a safeguard power would not necessarily give rise to such concerns. Since it would not involve a challenge to the substance of the decision to invoke or not to invoke the safeguard in question, a procedural challenge might stand a greater chance of success. For example, if the UK government were to invoke a safeguard provision without adhering to the procedural requirements of the provision invoked, as specified in the WA and the TCA, it is likely that the courts would be willing to intervene to restrain any such procedural omission. Thus, if the government were to invoke Protocol Article 16 without adhering to the procedural requirements laid down in Protocol Annex 7, such as the obligations to notify the EU of the invocation of the safeguard, to enter into consultations, and to wait one month following notification prior to taking safeguard measures, such omissions might be capable of being enforced as mandatory statutory requirements which had to be fulfilled as a precondition to the lawful exercise of the safeguard power in question. ${ }^{48}$

\subsubsection{Judicial Review under WA}

With respect to the Protocol, there are two routes for the judicial review envisaged in the WA: (i) the arbitration mechanism established under the WA; and (ii) CJEU jurisdiction. ${ }^{49}$

Any dispute concerning Protocol Article 16 between parties to the WA may be brought before the arbitration mechanism created under the WA. The parties must first seek to resolve a dispute amicably, via the Joint Committee, "by entering into consultations in good faith, with the aim of

46 Ibid, $\$$ 1-035-1-049.

$47 \mathrm{Eg}, R$. (on the application of Bancoult) $v$ Secretary of State for Foreign and Commonwealth Affairs (No 2) [2008] UKHL 61; [2006] 1 AC 453. D McGoldrick, 'The Boundaries of Justiciability' (2010) 59 International and Comparative Law Quarterly 981.

48 De Smith, $\$ \$$ 5-057-5-070.

49 See further Chapter 5. 
reaching a mutually agreed solution, ${ }^{50}$ Where no amicable solution is found, disputes may be referred to an arbitration panel which must deliver a ruling within twelve months of its establishment. ${ }^{51} \mathrm{~A}$ party that wishes the matter to be resolved with urgency - a likely scenario in the case of safeguard disputes - may make such a request to the panel. If the panel accedes to the request, it will make every effort to issue a ruling within six months. ${ }^{52}$

Once delivered, the panel's ruling will be binding on both parties who must 'take any measures necessary to comply in good faith with the arbitration panel ruling. ${ }^{53}$ Where the respondent has not complied with the ruling within a reasonable period of time, the complainant can request the panel to impose temporary remedies which will take the form of either a lump sum or a penalty payment. ${ }^{54}$ If payment is not made by the non-complying party, within a one month deadline following the determination of the remedy, the other party may temporarily suspend any part of the WA, except the citizens' rights provisions, or of any other agreement between the EU and the UK. ${ }^{55}$ Any suspension should, however, be proportionate to the breach of the obligation concerned and only apply so long as the breach of the WA persists. ${ }^{56}$

Protocol Article 12(4) also confers CJEU jurisdiction in relation to Protocol Article 5 (customs) and Articles 7 to 10 (technical rules, value added tax, electricity market and state aid). UK measures falling foul of these provisions can, for example, be the subject of a direct legal challenge by the European Commission before the CJEU via infringement proceedings. Article 12(4) also specifically mentions preliminary ruling procedures, which would allow domestic courts in the UK to refer questions on the validity of EU law to the ECJ. ${ }^{57}$

Protocol Article 16 does not fall within CJEU jurisdiction, but the question arises whether the CJEU may have a role to play where the UK commits a breach of Protocol provisions that do fall within its jurisdiction and seeks to justify such breaches by reference to Protocol Article 16. In Chapter 5, Wouters posits that while CJEU jurisdiction may be

\footnotetext{
50 Art 168 WA.

51 Art 173 WA.

52 Ibid.

53 Art 175 WA.

54 Art 178 WA.

55 Art 178(2) WA.

56 Art 178(2) WA.

57 Art 267 TFEU.
} 
triggered with respect to Protocol provisions that cross-reference provisions identified in Protocol 12(4), the same does not apply to provisions that contain no such cross-references. ${ }^{58}$ If this were so, it would have the effect of allowing the UK to evade CJEU jurisdiction by invoking Protocol 16 whenever it intended to commit breaches of Protocol Articles 5 and 7 to 10. To use a recent example, on 15 March 2021, the European Commission initiated infringement proceedings against the UK following the latter's decision to unilaterally extend grace periods allowing it to disapply certain aspects of Protocol Article $5 .^{59}$ In an alternate reality, where the UK had decided to package the unilateral extension as safeguard measure intended to avert serious economic and social difficulties, the invocation of Protocol 16 would arguably exclude the matter from the jurisdiction of the CJEU. Such outcome is, however, perfectly in line with the purpose of exclusive CJEU jurisdiction under Protocol 12(4) - that is, to protect the autonomy of the EU legal order and ensuring the uniform interpretation and application of EU law. In disputes where Protocol 16 is invoked in relation to Protocol Articles 5 and 7 to 10, the question is not whether EU law has been breached - the mere invocation of safeguards confirms that a breach of EU law has been committed - but, rather, whether the conditions for the invocation of safeguards have been met.

\subsection{Conclusion}

The safeguards regimes envisaged under Article 16 of the Protocol and Article 773 TCA differ from the WTO regime in terms of both their substantive and their procedural requirements. Broadly speaking, they seem to confer on the parties a considerable amount of discretion in deciding whether or not to apply safeguard measures. This has important repercussions in relation to future potential legal challenges. While there is likely to be some scope for the review of the exercise of safeguard powers, as a matter of both EU and UK law, that review under EU law is likely to be impacted by the onerous standing requirements which apply. Review in the UK is likely to be of limited effect due to the limited scope of the jurisdiction of the courts on an application for judicial review. It is also unlikely that the invocation by the UK of Protocol Article 16 would

58 See Chapter 5.

59 See European Commission Letter of Formal Notice of 15 March 2021, https://ec.europa .eu/commission/presscorner/detail/en/ip_21_1132. 
fall within the jurisdiction of the CJEU under the WA. The cumulative effect of this is likely to be that issues concerning invocations of the safeguard provisions of the WA and the TCA will predominantly be determined politically, with the courts occupying a subsidiary position perhaps confined to ensuring that the correct procedures are adhered to in the invocation of safeguard provisions. 